ESTUDIOS CERVANTINOS

205-217

\title{
CON NO SÉ QUÉ VISLUMBRES DE IRONÍA: INDICADORES Y MARCAS DE LA IRONÍA EN EL VIAJE DEL PARNASO ${ }^{l}$
}

Con no sé qué vislumbres de ironía: indicators and marks of irony in Viaje del Parnaso

Cristina Tabernero*

Resumen

En este artículo se analiza la ironía en el Viaje del Parnaso desde la perspectiva pragmalingüística. Tras una exposición resumida de los problemas literarios que ha generado la obra en cuestión, incluida casi unánimemente entre la poesía burlesca, se aplica la concepción lingüística a la estrategia empleada por Cervantes, haciendo hincapié en la ironía como elemento de la parodia y de la sátira y como procedimiento ecoico o polifónico. Se concluye la caracterización de la obra como ironía continuada inestable o heurística, en la que se aprecian ciertos indicadores o marcas que permiten una adecuada interpretación de los tercetos cervantinos. Destacan entre estos indicadores o marcas las palabras de alerta, el eufemismo, los juegos de palabras y la modalización epistémica.

Palabras clave: Ironía. Burla. Polifonía. Pragmática.

\section{Abstract}

This article analyzes the irony present in Viaje del Parnaso from a pragmalinguistic perspective. After a summarized explanation of the literary problems that the piece of work under consideration -which has almost unanimously been classified as burlesque poetry- has caused, linguistic conception has been applied to the strategy used by Cervantes, emphasizing the irony as an element of parody and satire as well as a polyphonic or echoic technique. Thus, this piece of work is classified as a continuous unstable or heuristic irony, in which some indicators or marks that enable an accurate interpretation of the Cervantine tercets are visible. Among these indicators or marks, alarm words, euphemisms, word plays and epistemic modalization stand out.

Key words: Irony. Mockery. Polyphony. Pragmatics.

\section{INTRODUCCIÓN}

Lejos queda la interpretación del Viaje del Parnaso como intento fallido de crítica literaria, relación elogiosa de la poesía y de los poetas coetáneos al autor y muestra fehaciente, además, del escaso valor de la producción poética cervantina ${ }^{2}$, en ningún caso, al menos, comparable al de su prosa; por el contrario, esta obra ha sufrido en las últimas décadas una importante revisión, que ha modificado por completo las

\footnotetext{
${ }^{1}$ Este trabajo forma parte de los resultados del proyecto HAR2012-31536, Discurso y poder, lengua y autoridad en el mundo hispánico (siglos XVI-XVII), subvencionado por el Ministerio de Economía y Competitividad.

${ }^{2}$ Para la revisión bibliográfica a este respecto, ver Mata (55-59), Trabado (37-74) y Santos de la Morena (305).
} 


\section{Cristina Tabernero}

ideas vertidas respecto de la intención de su autor y acerca del carácter del texto, permitiendo su entrada en el género de la poesía burlesca (Balcells).

En las primeras lecturas interpretativas del siglo XIX algunos comentaristas del poema cervantino destacaron su importancia como fuente de conocimiento del pensamiento y del interior de Cervantes (James Y. Gibson), apuntaron ya hacia la presencia de la burla y la parodia en el texto y ayudaron a contextualizarlo histórica y culturalmente en su época (B. Croce). En esta misma línea, especialmente en el apunte del tono burlesco, prosiguieron las ediciones de Schevill y Bonilla o la de Rodríguez Marín, pero fue sobre todo M. Herrero, cuya edición póstuma manejamos en este trabajo (Herrero ${ }^{3}$ ), quien anticipó la coexistencia de ficción y realidad en la que se ven envueltos el escritor y el lector.

Por su parte, J. Canavaggio (37-38) colocó la clave interpretativa del poema en la identificación de las distintas instancias enunciativas que cohabitan en sus tercetos encadenados - Cervantes escritor, narrador y personaje- y E. Rivers, aunque reconoce la imposibilidad de una lectura definitiva ${ }^{4}$, afirma que cualquier lectura histórica y literaria debe partir de la consideración del poema dentro de la tradición de la sátira menipea clásica; este género, en palabras de Rivers (114), "también es la máscara literaria que da forma al rostro que el escritor, más o menos autobiográficamente, quiere presentar al lector" y en él se incluyen los elementos burlescos, "que abarcan también una parodia de la poesía épica" (114).

Lo cierto es que en la mayoría de los estudios recientes la vuelta sobre el Viaje del Parnaso cervantino ha ido acompañada de un tono de reivindicación del valor literario de la obra o, al menos, de un intento de interpretación atinada, más allá de la superficialidad de una lectura que podría denominarse literal (Gracia, 333). En este sentido, según se acaba de exponer, se ha hecho hincapié esencialmente en dos aspectos: el primero de ellos, la burla, el humor, la socarronería, la parodia, la ironía y la sátira, lo que ha permitido incluir el Viaje entre la poesía burlesca del Siglo de Oro (Cacho, 19), y el segundo, la polifonía, que deja escuchar voces diferentes que juegan entre la realidad y la ficción. Bajo la conjugación de ambas, la ironía que recorre realidad y ficción, que da lugar a la sátira de la sociedad en general y del mundo poético en particular, se descubre el encomio del valor de la auténtica poesía ${ }^{5} \mathrm{y}$, al decir de algunos, una auténtica autoalabanza de la talla poética de Cervantes (Sansone, 61), atenuada por el uso de la autoironía (Campana), cuestión esta de la (auto)estima poética que algunos autores ponen en duda por el carácter negativo que la ironía imprime a aquellas realidades o significados a los que se aplica (Gutiérrez, 1047). De carácter metaliterario han hablado otros: "una obra sobre escritores y para escritores" (1047), que encuentra su referente real en el Madrid literario del siglo XVII,"una realidad

\footnotetext{
${ }^{3}$ En la bibliografía recojo la edición de Herrero en la entrada correspondiente a Cervantes.

${ }^{4}$ En este sentido ver Gutiérrez (1044).

${ }^{5}$ En esta línea de interpretación ver Gracia; Santos.
} 
sociocultural salpimentada de ironía, burla y parodia mitológica ${ }^{6}$ : el comienzo de escritores cortesanos de comienzos del siglo XVII" (1048).

Así pues, el componente irónico, que recorre todo el poema, convirtiéndose en elemento definidor del propio texto: "En el caso concreto de la ironía, su presencia en el Viaje es ontológica y no instrumental (...); no es tanto microtextual cuanto macrotextual" (1047), ha sido profusamente mencionado pero escasamente atendido.

Precisamente por la importancia de la ironía en el poema, por la atención que la lingüística ha prestado en los últimos años a este fenómeno pragmático, que se define como procedimiento ecoico o polifónico, y por la relevancia que la polifonía reviste en el Viaje, como se ha dicho líneas más arriba, consideramos que un análisis desde esta perspectiva ha de contribuir a esa comprensión "imperfecta" de la obra cervantina.

\section{LA CONCEPCIÓN LINGÜÍSTICA DE LA IRONÍA}

Tradicionalmente, la ironía se ha calificado, desde la Retórica clásica, de tropo y figura, de pensamiento y de dicción a un tiempo. De hecho, Quintiliano mantenía que la ironía continuada se convertía de tropo en figura de pensamiento (Marimón, 21-22). Desde este punto de vista este procedimiento se ha definido como juego de contrarios o decir lo contrario de lo que se piensa, esto es, como "estrategia argumentativa con tres ingredientes básicos: simulación, contradicción y juicio de valor negativo" (Bruzos, 26 y Ruiz Gurillo y Padilla, Presentación). Más adelante, la lingüística adaptó a su ámbito la terminología retórica y en la misma línea definió la ironía como "burla por antífrasis o una antífrasis con función de burla" (Kerbrat-Orecchioni, 256). Sin embargo, la reformulación de estas teorías por parte de sus propios autores ha mostrado que ironía y antífrasis no se identifican necesariamente y que, en consecuencia, el rasgo distintivo de la primera reside en su valor ilocutivo de burla o de crítica negativa, es decir, en su componente pragmático, lo que asocia de nuevo los planteamientos lingüísticos con los retóricos (Bruzos, 28).

Así pues, la consideración de la ironía en su funcionamiento pragmático o discursivo resulta unánime en los estudios lingüísticos más recientes: "la ironía es 1) una transgresión ilocutiva manifiesta, cuyo reconocimiento fuerza al intérprete a no conformarse con el sentido literal del enunciado y a emprender 2) un proceso de reinterpretación o de reconstrucción del sentido irónico" (Bruzos, 30-31).

En definitiva, desde las diferentes teorías pragmáticas, la ironía se ha definido como una violación de alguna de las máximas conversacionales de Grice ${ }^{7}$, dentro de la teoría de los actos de habla, como una violación transparente de la máxima de sinceridad (Haverkate), que precisamente por su explicitud no puede identificarse en ningún caso con la mentira. En este último caso, la ironía persigue un efecto retórico en los interlocutores, que, en ocasiones, puede resultar ambiguo, ya que no es posible saber

\footnotetext{
${ }^{6}$ Para la construcción del humor en el poema mediante símbolos y emblemas, ver Arellano.

${ }^{7}$ Torres (443) y Ruiz Gurillo (872-873).
} 


\section{Cristina Tabernero}

a ciencia cierta si la enunciación es encomio o burla; para solucionar este conflicto se ha distinguido entre ironía estable o correctiva, por la que un término invalida o contradice al otro, e ironía inestable o heurística -y esta es la que nos interesa especialmente-, que produce un efecto final paradójico de las cosas (Bruzos, 41).

Finalmente, desde la teoría de la enunciación, la ironía se describe como enunciación polifónica, esto es, aquella que consiste en la introducción por parte del locutor de un punto de vista diferente del suyo y del que aquel se distancia y se burla implícitamente (Reyes; Fuentes y Alcaide; Bruzos). Ahora bien, como señala Bruzos (45), el conflicto que se plantea en la ironía entre la perspectiva del locutor y la del enunciado no resulta siempre claro:

En el caso de la ironía inestable (Booth) o heurística (Muecke), la verdadera posición del primero resulta voluntariamente ambigua. Entonces la ironía permite argumentar en dos sentidos opuestos sin la necesidad de comprometerse de manera definitiva con ninguno de ellos ( 45).

No dejaremos de apuntar aquí que tal vez esta distinción pragmalingüística convenga a la lectura del Viaje del Parnaso cervantino cuando se ha señalado la relevancia de la ironía como elemento vertebrador del poema y su especial dificultad de interpretación, que puede oscilar del encomio a la burla. De ironía inestable o heurística podríamos calificar entonces la obra de Cervantes.

En cualquier caso, tanto la retórica como la lingüística y la pragmática destacan el enorme poder persuasivo de la ironía y, en consecuencia, su excelente rendimiento como estrategia argumentativa, que, por alguna razón, provoca en el interlocutor una receptividad mucho mayor que otras (Fuentes y Alcaide, 157).

\section{LA IRONÍA COMO FENÓMENO PRAGMÁTICO EN EL VIAJE DEL PARNASO}

De acuerdo con la definición de ironía como fenómeno pragmático, que "solo se percibe en contexto y depende de las intenciones del locutor y de las capacidades interpretativas del interlocutor", son varios los trabajos que han intentado establecer la existencia de marcas o indicadores lingüísticos de esta estrategia discursiva. Precisamente la dependencia que presenta el enunciado irónico respecto del contexto vuelve muy complicada la tarea de concretar estas marcas o indicadores en una lista de fenómenos lingüísticos, pues, según se ha recordado, la identificación de la ironía exige la presencia en el receptor de varias presuposiciones anteriores en el acto de habla que permitan a aquel una correcta interpretación (Reus, 297-298). Esta dificultad se acentúa cuando el texto irónico se desarrolla en la materialidad escrita y no en la oral, de manera que se pierde la entonación, uno de los principales identificadores de la ironía (Torres, 32; Reus, 304). De hecho, como resultado de esta complejidad, los autores que han trabajado en este tema han visto la necesidad de distinguir las marcas de los indicadores, entendiendo las primeras como "guías que ayudan a la interpretación irónica del 
enunciado" y los segundos "como elementos que contienen ironía en sí mismos" (Ruiz Gurillo y Padilla, Presentación, 8).

Por tanto, las clasificaciones existentes hasta el momento han sido de carácter muy general, aunque resultan considerables los últimos avances hacia una nómina de estrategias que perfile la ironía en sus marcas lingüísticas y no lingüísticas: D.C. Muecke distingue tres formas de contradicción - entre texto y contexto, entre texto y cotexto y entre texto y texto-; algo más concreta resulta la lista de P. Schoentjes al referirse a la mímica y gestos, al tono, a signos de puntuación, a palabras de alerta, a repeticiones, a yuxtaposiciones, a simplificaciones y a desvíos estilísticos (lítotes, hipérbole y oxímoron), el paratexto y la inteligencia en cuanto conocimiento compartido por los participantes; por su parte, el grupo GRIALE ${ }^{8}$, tomando como punto de partida la estructura triple básica del discurso de F. Poyatos, se refiere a tres elementos: los kinésicos, los paralingüísticos -voz, timbre, intensidad, tono- y los lingüísticos -signos de puntuación, palabras de alerta, repeticiones, yuxtaposiciones, evidenciales, reinterpretación de fraseologismos, lítotes, hipérboles y oxímoron-, sin que las listas que se ofrecen en cada uno de ellos puedan considerarse todavía cerradas.

Así pues, partiremos de esta concepción pragmática de la ironía para acometer su análisis en el Viaje del Parnaso, tratando de identificar los procedimientos lingüísticos -ya sean estos marcas o indicadores-de los que se sirvió Cervantes para construir su universo discursivo.

\subsection{MARCAS E INDICADORES}

Evidentemente, como se ha señalado más arriba, las manifestaciones de la ironía no coinciden en el texto escrito y en el oral; el segundo posee algunos recursos, los que acompañan a su propia materialidad y concepcionalidad, entendida esta en el sentido de Koch y Oesterreicher, que por la misma razón no pueden estar presentes en el primero. En algunos trabajos (Weinrich y Warning, cit. por Torres) se ha llegado a apuntar incluso la imposibilidad de describir formalmente indicador irónico alguno y la inviabilidad de la comunicación irónica escrita, a no ser que se posea un conocimiento personal de las creencias del autor ${ }^{9}$.

Sin embargo, se puede hablar de modo general, como han demostrado distintos estudios (Ruiz Gurillo y Padilla, Dime cómo ironizas; Reus, 297), de dos maneras distintas de formular la ironía. La primera o ironía focalizada se produce en un enunciado concreto y se vincula al contexto situacional y lingüístico en tanto que suele

\footnotetext{
${ }^{8}$ Grupo de investigación acerca de la ironía y el humor en español, vinculado al área de Lengua española del Departamento de Filología española, Lingüística General y Teoría de la Literatura de la Universidad de Alicante y dirigido por Leonor Ruiz Gurillo (http://dfelg.ua.es/griale/index.html).

Para las clasificaciones que se acaban de enunciar y para los elementos que se señalan a continuación, ver Alvarado.

${ }^{9}$ Estas ideas de Weinrich y Warning son citadas por Torres y por Reus, que reproduce las palabras de Torres (298).
} 


\section{Cristina Tabernero}

constituir respuesta a otro enunciado anterior, que sería el ecoizado por el irónico ${ }^{10}$; la segunda o ironía continuada se da a lo largo de todo un texto y se basa en el conocimiento compartido entre los interlocutores, por lo que se vincula al contexto situacional y sociocultural.

Es con esta formalización de ironía continuada como nos presenta Cervantes ${ }^{11} \mathrm{su}$ Viaje del Parnaso, cuyo sentido, en efecto, nunca literalmente enunciado, se sobrentiende gracias a la presencia de marcas e indicadores lingüísticos y, sobre todo, por el conocimiento enciclopédico que comparten los interlocutores.

Es decir, en este poema burlesco, construido de parodia y sátira, la ironía se erige como componente esencial ${ }^{12}$ (Hutcheon) en el modo que describiremos a continuación.

\section{Palabras de alerta}

Schoentjes otorga esta denominación a voces que se emplean para "exagerar la fuerza de un enunciado o volverlo sospechoso" (143) por medio de un cambio de registro, de un contenido encomiástico, de la valoración, etcétera (Alvarado, 7); se trata, por tanto, de indicadores de la ironía.

En efecto, la bibliografía sobre Cervantes ha señalado la inclinación del autor por la ruptura de la elevación poética mediante términos o expresiones que suponen un desajuste estilístico, lo que provoca un efecto humorístico. Este contraste de registros implica la entrada de un enunciador distinto del locutor, del que este se distancia, otorgando de este modo al pasaje un carácter burlesco. Este es el efecto que se consigue con la entrada de voces inconvenientes a los temas tratados, que en la época se adscribían al uso "familiar", según la denominación de Autoridades, como reverendo (DA, s.v.) ("capricho reverendo", I, 4), e incluso "jocoso y vulgar" como pancho (el pancho lleno, I, 35), recado ("dar a los Lupercios un recado", III, 165), la voz de germanía maco o fraseologismos como sin blanca o Dios es Cristo ("Contó, cuando volvió el poeta solo/ y sin blanca a su patria, lo que en vuelo" I, 23; "de rumbo, de hampo y Dios es Cristo" II, 380).

También han de considerarse palabras de alerta aquellas que poseen referentes que poco tienen que ver con el mundo poético, esto es, que el receptor interpreta como discordantes por el conocimiento enciclopédico compartido con el enunciador. Sucede de tal manera con los "sujetos fregoniles" (IV, 51), las "cosas de agibílibus rateras" (I, 80)

\footnotetext{
${ }^{10}$ Resulta más propio de la lengua oral.

${ }^{11}$ En las páginas siguientes realizamos un análisis de la obra cervantina y, en consecuencia, de los mecanismos lingüísticos empleados por Cervantes para la expresión de la ironía en el español de su tiempo. Interesante sería, en este sentido, el cotejo con el original italiano en el que Cervantes declara haberse basado -el Viaggio di Parnaso, de Cesare Caporali- con el fin de comprobar si la intención irónica y paródica de la obra, tomada asimismo del autor italiano, se materializa en procedimientos similares.

En definitiva, se plantearían aquí dos problemas diferentes: el que afecta de un lado a la lingüística contrastiva, que intenta averiguar si lenguas diferentes funcionan de modo paralelo, y el que tiene que ver con la crítica literaria, que deslinda los elementos debidos a cada autor y la observación del género.

${ }^{12}$ Como ha señalado L. Hutcheon, la ironía constituye elemento esencial de la parodia y de la sátira.
} 
(Herrero, 361), el garrafo ("de pies y de manos y que ya me ahogo/ en otras linfas que las del garrafo", V, 131-132), las calabazas y los odres ("en un instante el mar de calabazas/ se vio cuajado, ..., V, 187; "también hinchados odres y valientes", V, 190) o el piezgo ("el piezgo de la boca atada", V, 235). Se incluyen asimismo en este grupo las voces que nombran disfemísticamente las materialidades más prosaicas, las realidades excesivamente humanas, como el sudor, el hipo, las legañas, las heces, los defectos físicos y las enfermedades, y los alimentos y las bestias menos refinadas ("que al hacer sus versos sude y hipe" II, 229; "trabaja un tundidor, suda y se anima", II, 422; "que han de sudar", IV, 513; "clara y sin legañas", II, 375; "las heces del mundo y de la escoria", III, 68; "uno sus escrementos recogía", VIII, 161; "se ha comido las uñas" (Adjunta, 340); "múevete a compasión el verme gafo de pies y manos" (V, 130-133), "tomóle al rojo Dios alferecía" (IV, 475), "tómanla por momento parasismos" (I, 175), "tal de algarrobas, con que el vientre llena", VIII, 161; "llevando a la piara gruñidora", V, 187; "cernicalos que son lagartijeros", V, 247).

También entre las palabras de alerta podrían incluirse aquellas que construyen metáforas que vulgarizan lo elevado -zaranda, zarandó, guilla, cosecha, granzones-, como sucede en el deslinde de poetas buenos y malos, comparado a la criba del grano (II, 400-408).

\section{Eufemismo}

Las expresiones o términos eufemísticos constituyen otro de los indicadores de la ironía, que provocan asimismo la burla deseada, ya sea mediante la poetización de realidades cotidianas, "así en abril como en el mes de enero" ('en cualquier momento') (I, 18), o como denominación encubierta de situaciones negativas, convertidas ya en tópicos, como la pobreza de los poetas: "La oportuna hora de dar sustento al estómago pobre, y más si ayuna" (III, 419-420).

También se ocultan calificaciones que de este modo devienen en sátira o crítica irónica; recuérdese, por ejemplo, la descripción de la otra poesía, la "falsa, ansiosa, torpe y vieja" (IV, 169):

Amiga de sonaja y morteruelo,

Que ni tabanco ni taberna deja.

No se alza dos, ni aun un coto del suelo;

Grande amiga de bodas y bautismos,

Larga de manos, corta de cerbelo.

(...)

Baco donde ella está su gusto anuncia (IV, 170-178).

Irónica por eufemística resulta asimismo la duda sobre la inteligencia de Adonis -“¡Oh valiente garzón, más que sesudo!” (V, 106)-, la descripción de los aposentos de las ninfas que se ahogan -"Las ninfas en sus húmidas alcobas" (IV, 52)-, la descripción de la mula sobre la que el poeta se dirige al Parnaso -"Llegó donde compró una mula 


\section{Cristina Tabernero}

antigua" (I, 8), "tartamudo paso" (I, 9)-, la falta de voluntad de los Argensola -"Que tienen para mí, a lo que imagino,/ la voluntad, como la vista, corta" (III, 179-180)-, o el baño en la fuente Castalia, -"Unos, no solamente se hartaron,/ sino que pies y manos, $y$ otras cosas/ algo más indecentes, se lavaron" (III, 370-373), "Porque los más, de bruces, y no a sorbos,/ el suave licor fueron gustando" (III, 377-378)-.

\section{Polinomios léxicos (amplificación y acumulación)}

La presencia de términos coordinados con algún tipo de relación semántica, -sinonimia, hiponimia, hiperonimia-, que se reitera a lo largo de todo el poema, sirve, en ocasiones, como indicador de la ironía. En los versos insistentemente citados acerca de la supuesta incapacidad poética de Cervantes, la cuasisinonimia de "trabajo y me desvelo" ayuda a la interpretación correcta:

Yo, que siempre trabajo y me desvelo

Por parecer que tengo de poeta

La gracia que no quiso darme el Cielo (I, 25-27)

De este modo sucede también en la alabanza que, a juicio de Cervantespersonaje, no merece Mosén Luis de Casanate, uno de los poetas arrojados por la nube:

Fue el uno aquel de quien Apolo fía

Su honra, Mosén Luis de Casanate,

Poeta insigne de mayor cuantía

El mismo Apolo de su ingenio trate;

Él le alabe, él le premie y recompense;

Que el alabarle yo sería dislate (III, 112-117).

A estos que acabamos de citar se añaden el "tasquen, roan, chupen" (III, 241) de las olas o el "columbro, miro y veo" (III, 313) de Lofraso, el "mandó, vedó, quitó, hizo y deshizo" (III, 357) de Apolo, el "se estrecha, encubre, encoge, acorta", referido a las calabazas-cabezas de los poetas que flotan en el mar (V, 231), el libro arrojado a las sienes de Jusepe de Vargas, que causa "terror, grima y espanto" (VII, 163) o la descripción de Pancracio, poeta de la Adjunta -"todo limpio, todo aseado y todo crujiendo gorgaranes" (Adjunta, 9)-.

\section{Derivación léxica}

Se emplea igualmente como procedimiento irónico la formación de derivados mediante aumentativos, como el "poetón valiente" (I, 19) o el "poetón ya viejo" (VIII, 409), el "poeta pobretón" e ignorante ("Dime, ¿por qué algún tanto no te alejas/ de la ignorancia, pobretón y adviertes/ lo que cantan tus rimas en tus quejas? III, 324), el "librazo" (VII, 224) de la Pícara Justina y el jabalí "colmilludo" que atacó a Adonis (V, 104), al lado de los diminutivos del "saltico" que recorre distancias insalvables (I, 32) 
(Herrero, 345), del "mancebito" aspirante a poeta de los últimos versos (VIII, 361) o del despectivo "poetillas rateros" de la Adjunta (195).

\section{Juego de palabras (dilogía)}

A menudo Cervantes se divierte con la polisemia de las voces en un juego de palabras conceptista, característico de los autores de la época (Herrero): "más duros en sus versos que los cantos ('piedras' y 'composición poética')" (II, 407); "Porque pone los pies ('extremidad' y 'unidad métrica') por do ninguno/ los puso, y con sus nuevas fantasías" (IV, 421), "Y lleva recogida la manada,/ que con la de los Cerdas ("pelo de caballería', 'apellido de la casa de Medinaceli', 'hembra del cerdo', Herrero, 726) simboliza" (V, 206-207), "Quedó con esto la verdad en punto, que aquí puede llamarse punto fijo ("norte', 'punto invariable', Herrero, 889)" (VIII, 281-282), "no mire en puntos, aunque los traiga sueltos en sus medias" ('cosas pequeñas, puntuales', 'agujero o roto de la media') (Adjunta, 285).

Como variación del juego de palabras puede considerarse la desautomatización de fraseologismos ${ }^{13}$, que Cervantes también emplea como estrategia para marcar la ironía en el caso, por ejemplo, de relatos paródicos, como la descripción de la mula que se lee en los primeros versos:

Era de ingenio cabalmente entero:

Caía en cualquier cosa fácilmente,

Así en abril como en el mes de enero (I, 16-18).

Evidenciales y modalización epistémica ${ }^{14}$

En el Viaje del Parnaso se observan estrategias epistémicas y evidenciales reiteradas, que representan, respectivamente, el grado de certeza sobre la información enunciada y la codificación lingüística del punto de vista. De este modo, estos indicadores $^{15}$, entre otros, avisan al lector de la parodia en el relato de la maravillosa e increíble lluvia de poetas, en el que el autor juega con las voces enunciativas consiguiendo un efecto irónico y burlesco por medio del eco de otro enunciador, en este caso el autor de artificios literarios:

\footnotetext{
${ }^{13}$ Este recurso consiste en aprovechar, en un juego lingüístico, los significados literales de las voces que forman parte del fraseologismo.

${ }^{14}$ No interesa al objeto de este trabajo especular acerca de la mayor o menor relación entre la evidencialidad y la modalización epistémica. En general se ha considerado la modalidad evidencial como un subtipo de la epistémica cuya función consiste en confirmar o introducir la duda en la expresión modalizada. Otros autores han distinguido entre ambas en virtud de la ausencia - epistémica- o presencia - evidencial- de valoración, considerando la primera como expresión de la probabilidad y la segunda como manifestación del punto de vista u opinión.

${ }^{15}$ Consideramos en este caso que los evidenciales y modalizadores epistémicos se comportan como indicadores de la ironía antes que como marcas.
} 


\section{Cristina Tabernero}

¡Oh maravilla nueva! ¡Oh caso raro!

Vilo, $y$ he de decillo, aunque se dude

Del hecho que por brújula declaro.

Lo que yo pude ver, lo que yo pude

Notar, fue que la nube, dividida

En dos mitades, a llover acude (II, 358-363).

(...)

Por no creer esta verdad estuve

Mil veces; pero vila con la vista,

Que entonces clara y sin legañas ${ }^{16}$ tuve (II, 373-375).

Esta marca se usa igualmente para presentar verdades comprobadas y evidentes como opinión personal o hecho sujeto a la conjetura:

Que tienen para mí, a lo que imagino,

La voluntad, como la vista, corta (III, 179-180)

Por lo demás, el poema en general abunda en este tipo de expresiones -“a lo que entiendo", "a mi parecer", "a lo que yo barrunto"- que, de forma burlona, ofrece como fruto de la inteligencia del enunciador verdades generalmente conocidas; se trata, creemos, de la parodia de usos expresivos propios de los textos literarios de la época (Herrero).

\section{Anteposición de adjetivos y colocaciones léxicas}

La colocación antepuesta de adjetivos, que construye, por otra parte, sintagmas que bien podrían considerarse colocaciones por su reiteración sistemática en la poesía renacentista, ayuda a la interpretación desde una perspectiva paródica acerca del mundo mitológico. De hecho, estas construcciones funcionaban por su poder identificador a modo de sobrenombres de los dioses: rubio Apolo, serena frente, rubio sol, las neptúneas alas, el del alígero calzado, rubio Dios, el febeo aliento, etc. Como sucede en la ironía, se comportan como secuencias fácilmente identificables por el universo lector de la época cervantina y especialmente por aquellos que cultivan el arte de la poesía; intertextos, en definitiva, que construyen la parodia del mundo literario.

\section{Otras marcas e indicadores}

Finalmente, humor e ironía se consiguen con el uso de innovaciones gramaticales como la creación de variación genérica a sustantivos invariables (giganta, muso, ni monte ni monta), mediante compuestos neológicos en los que se aprecia motivación semántica (poetambre), hipérboles - "Poníanseme yertos los cabellos,/ de temor no encontrase algún poeta/ (de tantos que no pude conocellos)/ que con puñal

\footnotetext{
${ }^{16}$ Como se comprueba en este caso, pueden acumularse los indicadores de la ironía (ver más arriba lo señalado respecto de las palabras de alerta).
} 
buido o con secreta/ almarada me hiciese un abujero/ que fuese al corazón por vía recta" (VIII, 425), "con un cuello tan grande y tan almidonado, que creí que para llevarle fueran menester los hombros de otro Atlante" (Adjunta, 10-11), "si la grandeza del cuello no lo impidiera" (34)- o conectores concesivos y causales, que funcionan como marcas discursivas del procedimiento analizado (Ruiz Gurillo): "que puedo ser poeta, aunque soy paje" (VIII, 438), "puesto que pienso que no tengo ninguno, todavía no me aseguro de la común suerte" (Adjunta, 4), "aunque sea hecha al prior de Guadalupe" (315).

\section{REFLEXIÓN FINAL}

"A lo bellaco", como respondió Cilenio en el capítulo VIII (164), escribe Cervantes su Viaje del Parnaso ${ }^{17}$, "con no sé qué vislumbres de ironía" (VIII, 165), ironía continuada o ironía macrotextual (\$2) conformadora del componente satírico, paródico y burlesco del poema, en el que se mezclan la sinceridad en la voz de otro o ironía y la sinceridad del autor. En definitiva, instancias enunciativas diferentes difícilmente identificables por el empleo de una ironía que puede asemejarse a la denominada como inestable o heurística en ese juego entre verdad e insinceridad explícita en el que resulta difícil deslindar cuál de las dos está presente en el enunciado.

En cualquier caso, los indicadores de la interpretación irónica (\$3.1) que hemos visto, entre los que destacan las palabras de alerta, el eufemismo, los polinomios léxicos y la modalización epistémica, apuntan sobre todo a aquellos episodios del poema en los que se adivina parodia del mundo literario, de modo que esta perspectiva pragmalingüística apoyaría el carácter metaliterario de la obra que han defendido algunos autores (Guerrero y Herrero).

Asimismo, no puede perderse de vista el empleo de la ironía, con el despligue de instancias enunciativas que implica, como sutil estrategia de autoencomio (Campana) en la medida en que la alabanza es emitida no por el autor sino por un enunciador, del que aquel se distancia. Es de este modo como la inexcusable negatividad de la ironía (Gutiérrez, 262) puede servir a la alabanza de aquello que se aleja de lo censurado.

\section{GRISO-Universidad de Navarra* Campus Universitario, s/n 31009, Pamplona, Navarra (España) ctabernero@unav.es}

\footnotetext{
${ }^{17}$ Aunque no es propósito de este artículo establecer la deuda de Cervantes con su modelo, los Viaggi de Caporali, recordamos la importancia que se ha concedido a la alusión cervantina en los versos iniciales de su poema como intención declarada de adscripción a una tradición literaria (Campana, 76); ya se ha dicho más arriba que la intención paródica y el género se tomarían del precedente italiano, a pesar de que, como señala $\mathrm{P}$. Campana (76), "[h]oy en día, la crítica está sustancialmente de acuerdo en considerar la influencia del poema del italiano como puramente circunstancial, y en estimar la obra cervantina como claramente superior a su modelo, e incluso muy poco parecida a la de Caporali, que habría sido utilizada como un "señuelo" para llamar la atención del lector y adscribir el Viaje a un género en boga (Riley, 497-498)".
} 


\section{OBRAS CITADAS}

Alvarado, Belén. "Las marcas de la ironía". Interlingüística 16 (2006): 1-11.

Arellano, Ignacio. "Más sobre el lenguaje emblemático en el Viaje del Parnaso de Cervantes", Lexis 23. 2(1999): 317-336.

Balcells, José María. "Viaje del Parnaso y la serie épico-burlesca española", en Actas del XI coloquio internacional de la Asociación de Cervantistas. Chul Park (coord.) Seúl: Universidad Hankuk de Estudios extranjeros, 2005: 549-556.

Bruzos, Alberto. "Análisis de la enunciación irónica: del tropo a la polifonía", Pragmalingüística 13 (2005): 25-49.

Cacho, Rodrigo. "El ingenio del arte: introducción a la poesía burlesca del Siglo de Oro", Criticón 100 (2007): 9-26.

Campana, Patrizia. "Encomio y sátira en el Viaje del Parnaso", Anales cervantinos 35 (1999): 75-84.

Canavaggio, Jean. "La dimensión autobiográfica del Viaje del Parnaso", Cervantes: Bulletin of the Cervantes Society of Americal 1 1-2 (1981): 29-41.

De Cervantes, Miguel. Viaje del Parnaso, edición y comentarios de Miguel Herrero. Madrid: CSIC, 1983.

— Viaje del Parnaso, edición de Francisco Rodríguez Marín. Madrid: Bermejo, 1935.

_ Viaje del Parnaso, edición de Rudolph Schevill y Alberto Bonilla. Madrid: Gráficas Reunidas, 1922.

Fuentes, Catalina y Alcaide, Esperanza. Mecanismos lingüísticos de la persuasión. Cómo convencer con palabras, Madrid: Arco-Libros, 2002.

Gracia, Jordi. "Viaje del Parnaso: un ensayo de interpretación”, en Actas del I Coloquio internacional de la Asociación de cervantistas, Ministerio de Asuntos Exteriores, Anthropos, 1990: 333-348.

Gutiérrez, Carlos M. "Ironía, poeticidad y decorum en el Viaje del Parnaso. Volver a Cervantes", en Actas del IV Congreso Internacional de la Asociación de Cervantistas. 2. Coord. BernatVistarini, Antonio Pablo. Palma de Mallorca: Universitat de les Illes Balears, 2001: 1043-1050.

Haverkate, Henk. "A SpeechActAnalysis of Irony”. Journal of Pragmatics 14 (1990): 77-109.

Hutcheon, Linda. "Ironía, sátira y parodia. Una aproximación pragmática a la ironía". De la ironía a lo grotesco. Ed. Hernán Silva. México: Universidad Autónoma Metropolitana Iztapalapa, 1992: 173-193.

Kerbrat-Orecchioni, Catherine. L'implicite, Paris: Colin, 1986.

Koch, Peter y Oesterreicher,Wulf. Lengua hablada en la Romania: español, francés, italiano. Trad. de Araceli López Serena. Madrid: Gredos, 2007. 
Marimón, Carmen. "La retórica", en Dime cómo ironizas y te diré quién eres. Una aproximación pragmática a la ironía. Ed. Leonor Ruiz Gurillo y Xosé Antonio Padilla. Frankfurt: Peter Lang, 2009: 13-44.

Mata, Carlos. "Veinte poemas de amor y una canción desesperada de Miguel de Cervantes Saavedra”, Mapocho. Revista de Humanidades 57 (2005): 55-88.

Muecke, Douglas Colin. Irony, Londres: Methuen, 1970.

Poyatos, Fernando. La comunicación no verbal. 3 vols. Madrid: Istmo, 1994.

Reus, Francisco. "Cómo se manifiesta la ironía en un texto escrito", en Dime cómo ironizas $y$ te diré quién eres. Una aproximación pragmática a la ironía. Ed. Leonor Ruiz Gurillo y Xosé Antonio Padilla. Frankfurt: Peter Lang, 2009: 293-305.

Reyes, Graciela. La pragmática lingüistica. Barcelona: Montesinos, 1990.

Rivers, Elias L. “Cómo leer el Viaje del Parnaso?”, en Actas del III Coloquio internacional de la Asociación de cervantistas. Ministerio de Asuntos Exteriores: Anthropos, 1993: 105-116.

Ruiz Gurillo, Leonor. "Las 'marcas discursivas' de la ironía”. Los caminos de la lengua. Estudios en homenaje a Enrique Alcaraz Varó. Ed José Luis Cifuentes, Adelina Gómez, Antonio Lillo, Francisco Yus. Alicante: Servicio de Publicaciones de la Universidad de Alicante, 2010: 871-886.

Ruiz Gurillo, Leonor y Xosé Antonio Padilla. "Unas palabras de presentación”, en Dime cómo ironizas y te diré quién eres. Una aproximación pragmática a la ironía. Ed. Leonor Ruiz Gurillo y Xosé Antonio Padilla. Frankfurt: Peter Lang, 2009: 7-9.

Sansone, Giuseppe "El Viaje del Parnaso: testimonio de una discontinuidad", en Actas del II Coloquio de la Asociación de Cervantistas. Barcelona: Anthropos, 1991: 57-64.

Santos de la Morena, Blanca. "Cervantes recreado por sí mismo en el Viaje del Parnaso: reflexiones sobre su concepto de poesía", Recreaciones quijotescas y cervantinas en la narrativa. Ed. Carlos Mata. Pamplona: EUNSA, 2014: 305-312.

Schoentjes, Pierre. La poética de la ironía. Madrid: Cátedra, 2003.

Torres, María Ángeles. "Teorías lingüísticas del humor verbal", Pragmalingüistica 5-6. (1997-1998): 435-448.

Trabado, José Manuel. Poética y pragmática del discurso lírico. El cancionero pastoril de La Galatea. Madrid: CSIC, 2001. 